\title{
Meteorological factors controlling low-level continental pollutant outflow across a coast
}

\author{
D. L. Peake ${ }^{1}$, H. F. Dacre ${ }^{1}$, J. Methven ${ }^{1}$, and O. Coceal ${ }^{2}$ \\ ${ }^{1}$ Department of Meteorology, University of Reading, Earley Gate, \\ Reading, Berkshire, RG6 6BB, UK \\ ${ }^{2}$ National Centre for Atmospheric Science (NCAS), Department of Meteorology, University of Reading, Earley Gate, \\ Reading, Berkshire, RG6 6BB, UK \\ Correspondence to: H. F. Dacre (h.f.dacre@ @rdg.ac.uk)
}

Received: 11 March 2014 - Published in Atmos. Chem. Phys. Discuss.: 30 April 2014

Revised: 14 October 2014 - Accepted: 30 October 2014 - Published: 15 December 2014

\begin{abstract}
Coastal outflow describes the horizontal advection of pollutants from the continental boundary layer (BL) across a coastline. The outflow can ventilate polluted continental BLs and thus regulate air quality in highly populated coastal regions. This paper investigates the factors controlling coastal outflow and quantifies their importance as a ventilation mechanism. Tracers in the Met Office Unified Model (MetUM) are used to examine the magnitude and variability of coastal outflow over the eastern United States during summer 2004. Over the 4 week period examined, ventilation of tracer from the continental BL via coastal outflow occurs with the same magnitude as vertical ventilation via convection and advection. The relative importance of tracer decay rate, cross-coastal advection rate, and a parameter based on the relative continental and marine BL heights on coastal outflow is assessed by reducing the problem to a time-dependent box model. The ratio of the advection rate and decay rate is a dimensionless parameter which determines whether tracers are long-lived or short-lived. Long- and short-lived tracers exhibit different behaviours with respect to coastal outflow. Short-lived tracers exhibit large diurnal variability in coastal outflow but long-lived tracers do not. For short-lived tracers, increasing the advection rate increases the diurnally averaged magnitude of coastal outflow, but this has the opposite effect for very long-lived tracers. By using the box-model solutions to interpret the MetUM simulations, a land width is determined which represents the distance inland over which emissions contribute significantly to coastal outflow. A land width of between 100 and $400 \mathrm{~km}$ is found to be representative for a tracer with a lifetime of $24 \mathrm{~h}$.
\end{abstract}

\section{Introduction}

Coastal outflow is a potentially important mechanism for the ventilation of continental boundary layers (BLs) and regulation of air quality in coastal regions. Human population tends to be concentrated in coastal regions and consequently so are pollutant sources from industrial and residential areas, as well as road traffic and other transportation. Episodes of poor regional air quality often occur in anticyclonic situations where the large-scale flow is relatively stagnant, reducing outflow, and vertical ventilation of the BL is also inhibited, for example by descending dry air creating a strong inversion at the BL top. In this paper, a month-long mesoscale model simulation of summer 2004 over the eastern side of North America is used to investigate the relative importance of coastal outflow and vertical ventilation for pollutant levels within the continental BL. In addition, the evolution of the tracer distribution is summarised in terms of a box model with only a few parameters controlling the behaviour. The box model is sufficiently simple to have analytic solutions, but is also capable of describing the diurnal and synoptic timescale variability in tracers in the mesoscale model.

Stratified layers of pollutants over oceans have been observed by many studies (Paluch et al., 1992; Müller et al., 2001; Davis et al., 2012). Pollutants exported above the marine BL (MBL) have longer lifetimes (Dickerson et al., 1999), allowing more efficient long-range transport of pollutants (VanCuren et al., 2005; Holzer and Hall, 2007). For example, distinct layers of pollution have been observed over the Indian Ocean at altitudes between $500 \mathrm{~m}$ and $3 \mathrm{~km}$ far 
from the Indian coast (Verma et al., 2006). Within the MBL the high humidity typically enables faster photochemical processing (via higher $\mathrm{OH}$ radical concentrations, e.g., Real et al. (2008)) and soluble species also experience deposition to the surface. Cain et al. (2012) used a Lagrangian model to quantify the integrated effects of chemical and physical processes on the composition of air masses undergoing longrange transport. For example, while the instantaneous rate of ozone change is dominated by photochemical loss, the ozone concentration is actually most sensitive to physical parameters which control mixing of precursors and deposition of species such as nitric acid to the ocean. These physical effects have a strong impact on the reactive nitrogen budget and therefore indirectly on ozone through the photochemistry. Furthermore, polluted air masses above the MBL can be decoupled from the surface by the inversion at the top of the MBL (Vickers et al., 2001), and are subject to higher wind speeds than tracer exported below $H_{\mathrm{MBL}}$ (Skyllingstad et al., 2005).

In this paper, the term "coastal outflow layer" will be used to describe the decoupling of pollution from the surface via the formation of an internal stable BL which occurs when there is horizontal transport from land to sea and the land BL is deeper than the MBL (as is typically the case on nonfrontal summer days) (Dacre et al., 2007). The coastal outflow layer lies above the MBL $\left(H_{\mathrm{MBL}}\right)$ but below the maximum height that the continental BL reaches during its diurnal cycle $\left(H_{\max }\right)$. Pollutants emitted over land can be mixed to the top of the continental BL during the day through vertical turbulent mixing and can then be exported horizontally above $H_{\mathrm{MBL}}$. Pollutants with a long enough lifetime can continue to undergo coastal outflow during the nighttime due to their remaining presence in the residual layer which is left behind as the continental BL height collapses at nightfall. Horizontal advection across the coast into the MBL is also quantified but will be shown to be over three times smaller than the export into the coastal outflow layer during the conditions examined.

Angevine et al. (2006) observed the formation of stable MBLs over the cool waters of the Gulf of Maine in the summer of 2004. A sharp cooling of 5 to $15 \mathrm{~K}$ occurred in the lowest (approximately) $100 \mathrm{~m}$ of air within $30 \mathrm{~min}$ of the air crossing the coast. Turbulence was greatly reduced in this layer of the atmosphere. Skyllingstad et al. (2005) performed a large eddy simulation and showed that turbulence was damped from the surface upwards while a maximum in turbulence remained at the top of the MBL for $20 \mathrm{~km}$ offshore. The decoupling from the surface occurred very quickly after air flowed over the cool sea, allowing pollutants exported by coastal outflow to become isolated from the surface flow. Fang et al. (2009) showed, in a study of 15 summers, that while the largest export events from the northeast USA were associated with the passage of extratropical cyclones, $35 \%$ of the total export took place during high pressure situations. This suggests that while the export associated with localised convection or coastal outflow events may be small, over the whole summer period it plays an important role in the ventilation of pollutants from the BL. However, they used the MOZART chemical transport model driven by National Centers for Environmental Prediction (NCEP) Global Forecast System (GFS) analyses at $1.9 \times 1.9^{\circ}$ resolution, which is too coarse to capture mesoscale flows such as sea breeze circulations. In this paper we will use a mesoscale model at $12 \mathrm{~km}$ resolution run with online tracers for 4 weeks. Its representation of the sea breeze circulation is evaluated.

The month chosen for investigation was during the intensive observing period of the ICARTT (International Consortium for Atmospheric Research on Transport and Transformation) experiment in summer 2004 (Fehsenfeld et al., 2006). ICARTT was an umbrella organisation for more than 100 collaborations that focused on transport and chemical transformation across the eastern USA and then spanning the North Atlantic to Europe. The observations of most relevance for this study were associated with flights of the NOAA WP3D aircraft and the ground-based network enhanced as part of the New England Air Quality Study (NEAQS), including more than 100 ground sites measuring chemical constituents and seven BL wind profilers measuring continuously throughout the period ( $5 \mathrm{~min}$ resolution). There were no prolonged periods of flow stagnation during this summer, and therefore there were no episodes of particularly poor regional air quality. However, there were marked episodes of cross-coastal pollutant transport, some of which were observed by research aircraft as the air crossed the Atlantic to the Azores and Europe (Methven et al., 2006; Owen et al., 2006). Chemical processing following air masses for several days during these ICARTT Lagrangian cases has been examined in detail by Real et al. (2008); Lee et al. (2011); Cain et al. (2012); Davis et al. (2012).

The simulations are performed using an operational numerical weather prediction model, the Met Office Unified Model (MetUM), to determine the meteorological variables controlling coastal outflow. The key factors are captured by reducing the problem to a box model with simplified meteorology. It is used to investigate the relative importance of three variables - tracer lifetime, cross-coastal wind speed and the ratio $H_{\max } / H_{\mathrm{MBL}}$ - in controlling coastal outflow. The box-model framework is applied to MetUM results and used to estimate the width of land over which emissions can contribute significantly to coastal outflow.

The MetUM and experimental design are described in Sect. 2 and the simulated winds are evaluated using wind profiler observations throughout the period. The time evolution of vertical trace gas profiles following air offshore in the ICARTT experiment are also compared with the simulated profiles of idealised tracer. The structure of the box model is introduced in Sect. 3 and used to quantify the relative magnitudes of ventilation from the BL over the eastern USA by coastal outflow and vertical transport. Evolution equations for the box model are derived in Sect. 4 and used to map out 


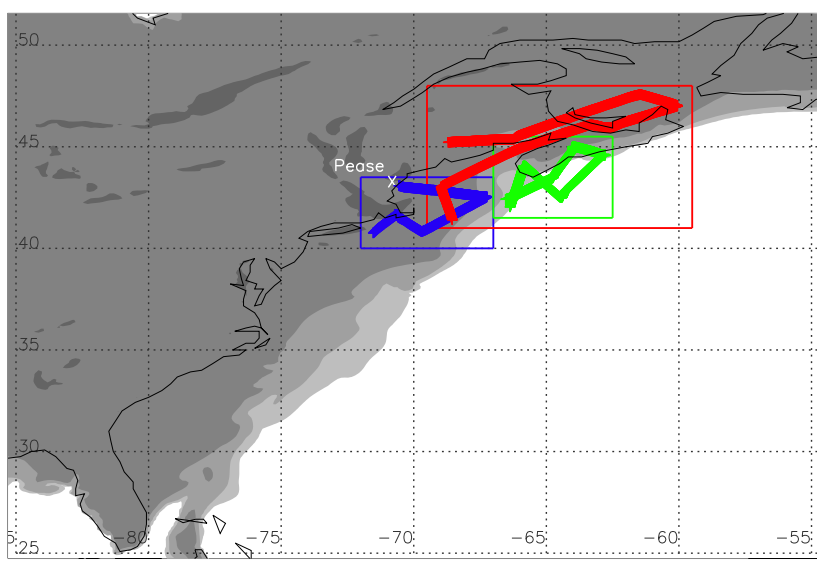

Figure 1. Tracer mixing ratio (shading) at 20:00 UTC on 20 July 2004, integrated from 20 to $1620 \mathrm{~m}$ a.s.1. Each shade represents a change in tracer concentration by a factor of 10 , with dark grey representing the highest mixing ratios. The cross marks the location of the wind profiler at Pease. The coloured lines show the segments aircraft flights performed on 20 (blue), 21 (green) and 22 July (red) that intercept the same polluted air mass. The coloured boxes represent the area over which modelled profiles are calculated for each respective day in Fig. $4 \mathrm{a}$

the behaviour of tracer in parameter space. The magnitude and diurnal variability of coastal outflow in the mesoscale simulation are interpreted using the box model in Sect. 5, which allows an understanding of the parameters that have the most influence on coastal outflow amounts.

\section{Four-week mesoscale model simulation}

\subsection{Model and experiment specification}

The MetUM is used to simulate the atmosphere over a domain containing the eastern half of the United States and the western half of the North Atlantic Ocean (Fig. 1). The 27 day period 00:00 UTC 13 July 2004 to 23:00 UTC 8 August 2004 was chosen to coincide with the ICARTT field campaign measurements. The MetUM version 6.1 is run with $5 \mathrm{~min}$ timesteps and a horizontal grid spacing of $0.11^{\circ}(\sim 12 \mathrm{~km})$ in both the longitude ( 250 grid points, a western boundary of $85.92^{\circ} \mathrm{W}$ ) and latitude (271 grid points, a southern boundary of $23.77^{\circ} \mathrm{N}$ ) directions. The simulation uses the v6.1 level configuration that was used for operational numerical weather prediction: 38 terrain-following model levels in the vertical, with 10 levels in the lowest $2 \mathrm{~km}$ above ground level, and model top at $39 \mathrm{~km}$. The simulation is initialised at $00: 00 \mathrm{Z} 13 / 07 / 04$ by re-gridding a global operational reanalysis from the European Centre for Medium-Range Weather Forecast (ECMWF) archive with a grid spacing of $0.25 \times 0.25^{\circ}$ lat/long, (approximately $22 \times 27 \mathrm{~km}$ ). Freerunning global MetUM forecasts (approximately $30 \times 65 \mathrm{~km}$ grid spacing) from each 6-hourly ECMWF operational re- analysis (available at 00:00 Z, 06:00 Z, 12:00 Z and 18:00 Z) provides hourly updates for the lateral boundary conditions used in the MetUM simulation. Sea surface temperatures are set to climatology.

An important aspect for this study is the diagnosis of BL depth from the model. At each horizontal grid point, the BL is defined by the number of turbulent mixing levels (NTML). For stable conditions this is the region in contact with the surface where the bulk Richardson number is smaller than 1 . For unstable conditions an adiabatic moist parcel ascent is performed in the model; ascent is stopped when the parcel becomes negatively buoyant. If the layer is well mixed the NTML is set to the parcel ascent top (inversion height). If the layer is cumulus-capped the NTML is set to the lifting condensation level (cloud base) (Lock et al., 2000). Above this layer the convection scheme mixes tracer from cloud base to the top of the cloud and below this level mixing is performed by the BL scheme. The maximum BL height at each land point every day was calculated. The 90th percentile of the maximum BL height was found to vary little from day to day, thus $H_{\max }$ was fixed at $2000 \mathrm{~m}$. The residual layer is defined to extend from the top of the BL to $H_{\max }$. The domain from height $H_{\max }$ to the model top will be described as the "free troposphere" since a very small proportion of tracer crosses the tropopause, but the integrals extend to model top to capture all the tracer mass.

Coastal outflow in the model will depend on the representation of horizontal flow across the coast. The quality of cross-coastal winds in the 27 day simulation is illustrated using observations taken with a $915 \mathrm{MHz}$ Doppler radar wind profiler sited at Pease, New Hampshire, which was at the focus of activity for the ICARTT experiment (Fehsenfeld et al., 2006). The profiler is part of the NOAA-DOE Cooperative Agency Radar Wind Profiler Network. The data have a vertical resolution of $60 \mathrm{~m}$ (Carter et al., 1995). At this location, the terrain is flat (site at $30 \mathrm{~m} \mathrm{ASL}$ ) and the coast is oriented in approximately the same direction as the average for the East Coast USA (see Fig. 1). Figure 2 shows the component of the horizontal wind perpendicular to the coast vs. height on a time series obtained from the MetUM and wind profiler. In both cases, the diurnal cycle has been filtered from the data using a running mean with a centred $24 \mathrm{~h}$ window. The synoptic variations are clearly represented in the model, indicating that the continuous update of its boundary conditions using analyses is sufficient to keep the synoptic scale evolution on track. There are events with larger differences. For example, the model simulates stronger offshore winds (by as much as $5 \mathrm{~m} \mathrm{~s}^{-1}$ ) near the surface from 4 to 5 August 2004. Away from the surface, for example at $2 \mathrm{~km}$, the correspondence is better. Over the whole time series, the standard deviation of the difference between the MetUM wind and profiler is less than $1 \mathrm{~ms}^{-1}$ at all heights. On average the wind speed in the MetUM is too low at the surface by $1 \mathrm{~m} \mathrm{~s}^{-1}$ and too strong at $800 \mathrm{~m}$ by $0.8 \mathrm{~ms}^{-1}$, without significant bias above $1500 \mathrm{~m}$. The height dependence of the bias is in part associated with 
(a) PEASE CROSS-COASTAL WIND: SYNOPTIC AVERAGE: UM Simulation

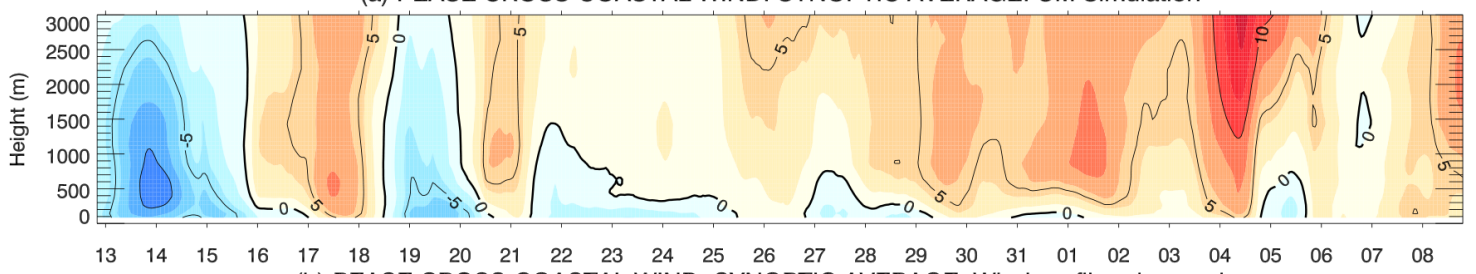

(b) PEASE CROSS-COASTAL WIND: SYNOPTIC AVERAGE: Wind profiler observations

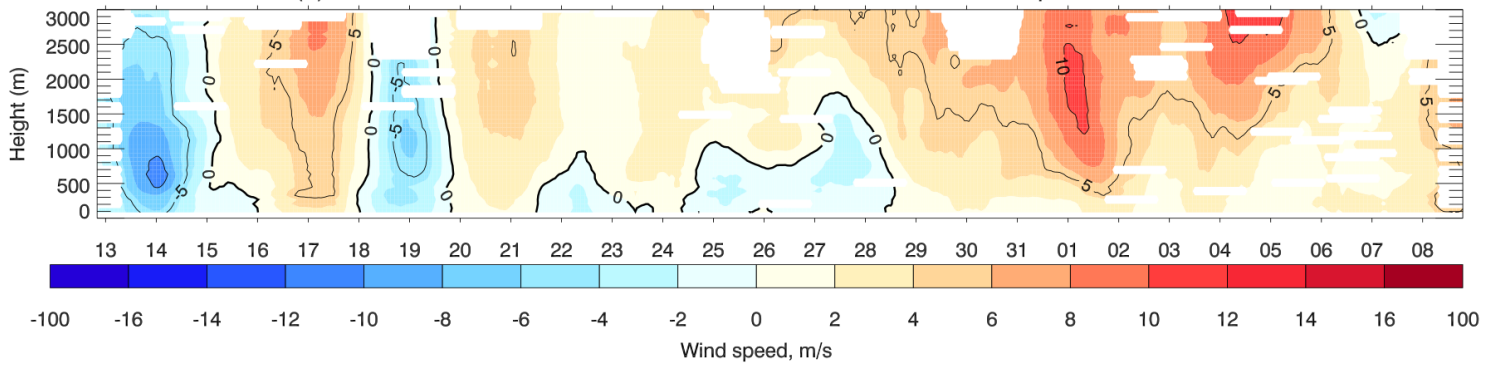

Figure 2. $24 \mathrm{~h}$ centred running average of cross-coastal direction wind speed at Pease (a) as simulated by the MetUM and (b) as observed by $915 \mathrm{MHz}$ wind profiler. The $x$ axis is labelled with the dates in July and August 2004. Positive wind speeds represent offshore flow and negative wind speeds represent onshore flow.

a weaker sea breeze circulation in the model. Comparing the model with the profiler at Pittsburgh, almost $500 \mathrm{~km}$ inland, shows a similar standard deviation, but smaller bias.

A diurnal composite was constructed for both data sets by removing the $24 \mathrm{~h}$ filtered data from the full winds and then compositing the remainder by averaging each hour of the day over the 27 days available. Figure 3 presents the comparison between the MetUM and wind profiler. The observations pick out a marked diurnal cycle in winds. Below $500 \mathrm{~m}$ the flow is offshore from 00:00 to 10:00 LT and then onshore from 11:00 to 23:00 LT, as expected for a sea-breeze circulation. The average amplitude of onshore or offshore surface winds is $2 \mathrm{~ms}^{-1}$. Above $500 \mathrm{~m}$, but below the top of the residual layer at $2000 \mathrm{~m}$, the offshore winds peak 2-4h after the maximum in the onshore sea breeze, indicative of a return circulation. The model captures some aspects of the sea breeze circulation. The nocturnal land breeze peaks too early in the night and appears to be too shallow and too weak at later times. The subsequent onshore flow at $1000 \mathrm{~m}$ is too strong. The evening sea breeze is better represented. Since both the synoptic and diurnal variability are represented in the simulation, it is reasonable to suppose that the variability in tracer transport can also be simulated realistically.

\subsection{Tracers in the model}

Pollution is represented within the MetUM simulation using two passive tracers, both with e-folding lifetimes of $24 \mathrm{~h}$, initialised and continuously emitted in the lowest model level uniformly over the land (as determined by the land-sea mask of the model). One tracer is transported by advection, parameterised convective mass fluxes and turbulent mixing, and the other is transported by advection and turbulent mixing only.
While the effects of the different transport processes on tracer distribution are not simply additive, by preventing one of the tracers being transported via convection the relative importance of convection can be quantified (Donnell et al., 2001). Figure 1 illustrates the tracer distribution at 20:00 UTC on 20 July 2004 coinciding with a segment of flight of the NOAA WP-3D aircraft (blue track). This was the first day during the major coastal outflow event of the ICARTT campaign period when several observation platforms (including the NOAA WP3-D aircraft tracks shown) followed pollution across the Gulf of Maine on 20, 21 and 22 July 2004. The tracer distribution shown is very similar to the distribution of ozone simulated by WRF-Chem (and averaged below $1700 \mathrm{~m}$ ) that is shown in Fig. 9 of Lee et al. (2011). Note that here a log scale is used to pick up the weaker concentrations further offshore. In both simulations at this time the tracer extends further from the coast in the location of the flight track and immediately to its south. The tracer gradient is closer inshore between Nova Scotia and Maine.

The total mass of tracer in the domain takes four days to reach a quasi-steady state, where the emission rate balances the tracer decay rate, and is approximately equal to $S \alpha$, where $S$ is the total source rate in $\mathrm{kg} \mathrm{s}^{-1}$ and $\alpha$ is the tracer lifetime. The uniform surface emission rate is $10^{-7} \mathrm{~kg} \mathrm{~m}^{-2} \mathrm{~s}^{-1}$ and the land area $3.91 \times 10^{12} \mathrm{~m}^{2}$. The emission rate was chosen to spin-up to an average steady state mixing ratio across the whole domain of the order of $500 \mathrm{ppbv}$ (assuming tracer is spread uniformly across the whole domain and land occupies half the domain).

The tracer experiment is idealised, assuming uniform emission rate across the entire land surface and a uniform decay rate (without chemical reaction). It is hard to evalu- 
(a) PEASE CROSS-COASTAL WIND: DIURNAL COMPONENT: UM Simulation

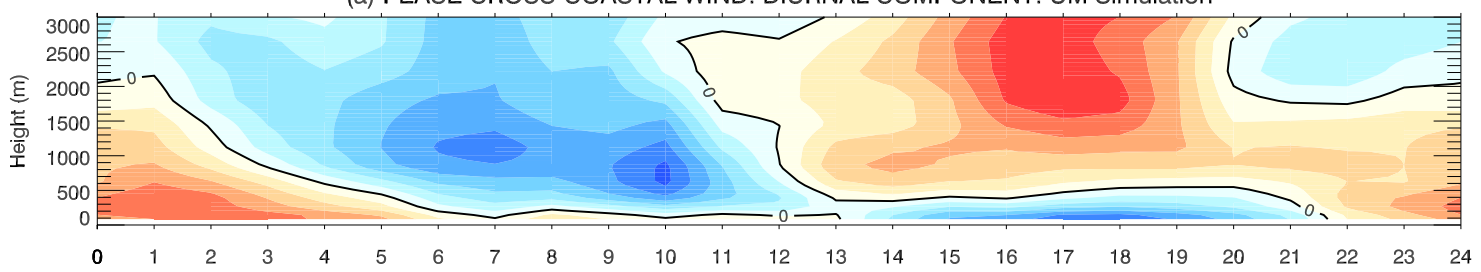
(b) PEASE CROSS-COASTAL WIND: DIURNAL COMPONENT: Wind profiler observations

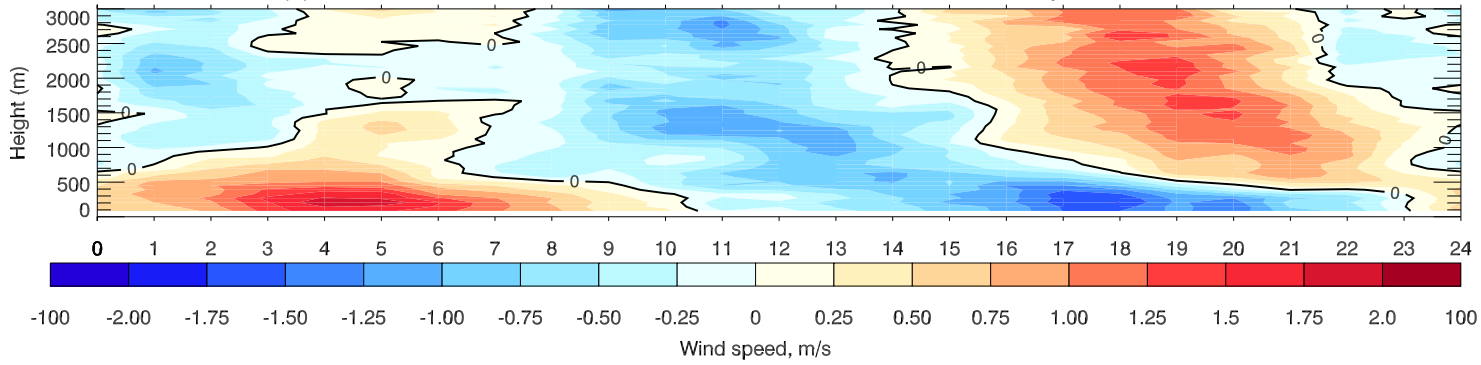

Figure 3. 27 day average diurnal component of cross-coastal direction wind speed at Pease (a) as simulated by the MetUM and (b) as observed by $915 \mathrm{MHz}$ wind profiler. The $x$ axis is labelled by the hour in local summer time (UTC-4). Positive wind speeds represent offshore flow and negative wind speeds represent onshore flow.

ate the simulation against data since pollutants have spatial and temporal variability in emissions. However, it would be desirable to know to what extent the idealised tracer yields information relevant to regional air quality.

The idealised tracer was chosen to have a lifetime of 1 day, which is comparable with typical advection timescales, as well as matching the timescale for BL height variation, which is dominated by the diurnal cycle. It will be shown that the most interesting behaviour occurs when the three timescales are comparable. However, none of the chemical species measured at high frequency during the ICARTT experiment, either at the ground or by aircraft, behave like a tracer with a uniform photochemical loss timescale of one day. Comparison is made with three species observed at high frequency (using $0.1 \mathrm{~Hz}$ data here). Carbon monoxide (CO) behaves most like a passive tracer. It is emitted directly by vehicles and industry and subject to advection and mixing. However, it has an average photochemical loss timescale in the troposphere of 25 days (Sze, 1977) and is therefore longlived relative to the idealised MetUM tracer. $\mathrm{NO}_{\mathrm{x}}$ (a combination of the active nitrogen oxides $\mathrm{NO}$ and $\mathrm{NO}_{2}$ ) has strong anthropogenic sources, but is short-lived. Far from emissions, it comes into a photochemical balance with longer lived species such as ozone. Ozone is a secondary pollutant that is produced chiefly through photochemistry rather than surface emission, has a strong diurnal cycle related to photochemistry and is subject to advection.

The heterogeneity of sources renders comparison with the idealised tracer over land difficult. So the approach taken here will be to compare over the western North Atlantic Ocean away from strong $\mathrm{CO}$ and $\mathrm{NO}_{\mathrm{x}}$ emissions. During the period 20-22 July 2004, offshore flow carried pollution from New York City across the Gulf of Maine. This episode was well observed by three aircraft (NOAA WP-3D, NOAA DC3 and NASA DC8), instrumented balloons in the BL, a ship and surrounding land-base stations (Fehsenfeld et al., 2006). Methven et al. (2006) also identified a Lagrangian connection between these flights and two flights of the DLR Falcon aircraft flying near Ireland and the UK on 25 and 26 July respectively. They named it the ICARTT Lagrangian Case 3 , and it has been used to examine long-range transport and chemical transformation (Real et al., 2008; Cain et al., 2012). The near-range chemical evolution of the air mass has been examined by several authors including Lee et al. (2011) and Davis et al. (2012). Here, segments of three NOAA WP-3D flights following the air mass on consecutive days are used to compare the time evolution of observed vertical profiles of trace gases with the idealised tracer simulation. The three segments of flight tracks are shown in Fig. 1. These segments are coloured blue (19:51-22:00 UTC 20 July 2004), green (16:06-19:00 UTC 21 July 2004) and red (15:00-19:24 UTC 22 July 2004). Each segment encompasses the Lagrangian match identified by Methven et al. (2006) as well as neighbouring vertical profiles up to approximately $4 \mathrm{~km}$.

Figure $4 \mathrm{~b}$ shows the $\mathrm{CO}$ measurements vs. altitude (measured by GPS) using the same colour code for the three consecutive flights. Profiles of the model tracer obtained from all points over the sea near the aircraft tracks are shown in Fig. 4a. Both model and observation show a maximum mixing ratio above the surface but below $700 \mathrm{~m}$ altitude, near the top of the MBL at these locations. Mixing ratio decreases with height above this. At all altitudes mixing ratios decrease with time. A notable difference is that the idealised tracer decreases more rapidly with height than $\mathrm{CO}$. This is a consequence of the much shorter tracer lifetime. As a result of the exponential decay with time away from source, a faster de- 

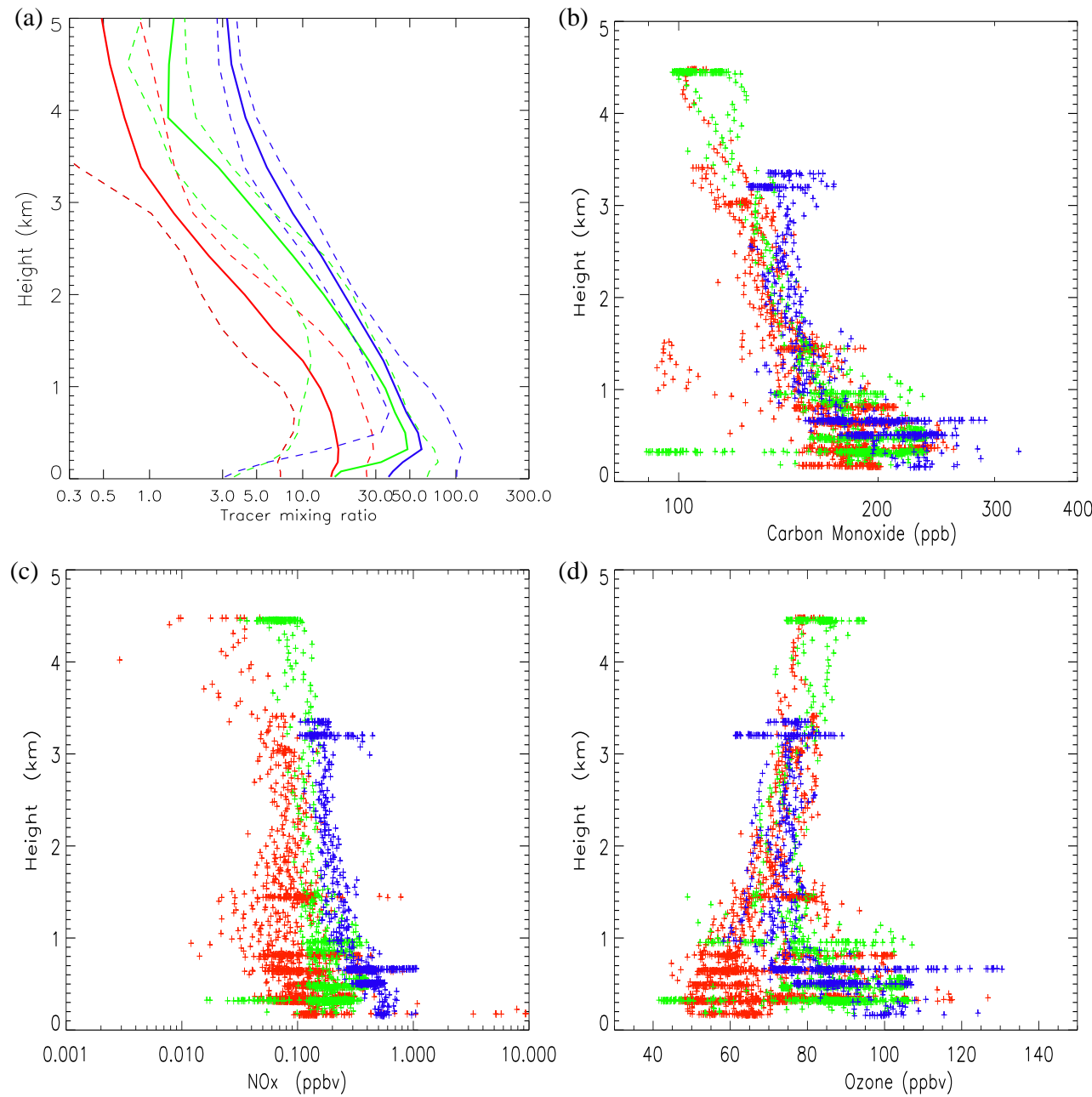

Figure 4. (a) Vertical profiles of tracer mixing ratio from the MetUM simulation on 20 (blue), 21 (green) and 22 (red) July 2004 . Profiles are averaged over sea points only within the rectangles shown in Fig. 1. 50th percentile (solid) and 25/75th percentiles (dashed). (a) Measurements of carbon monoxide (ppbv) vs. GPS altitude on 20 (blue), 21 (green) and 22 (red) July 2004 taken along the segments of NOAA WP-3D aircraft flight tracks shown in Fig. 1. (c) Vertical profile of $\mathrm{NO}_{\mathrm{x}}$ (ppbv). (d) Vertical profile of ozone (ppbv).

cline with height would be expected for shorter-lived tracers subject to the same transport and mixing processes, reflecting the age spectrum of air at each level. Therefore, a log scale is used to plot both model and observations to emphasise the roughly exponential profile below $4 \mathrm{~km}$. In an idealised scenario where there were no emissions influencing the air mass from 20 July 2004 and the air mass was surrounded by air with much lower mixing ratio, the profile would be expected to retain its slope but shift towards lower concentration, as is observed approximately. Furthermore, in both the model and observations the profile is steeper on 20 July 2004 than on the subsequent days, indicating that the transport and mixing in the model is a good representation of the processes happening in the atmosphere.

A similar exponential profile was measured for $\mathrm{NO}_{\mathrm{x}}$ with a marked decline in mixing ratio with time (Fig. 4c). The steep slope of the $\mathrm{NO}_{\mathrm{x}}$ profiles is at first surprising given its short lifetime. However, the ozone profiles (Fig. 4d) show a marked increase in ozone with altitude above $1 \mathrm{~km}$. Photochemistry strongly influences both profiles, although the constant slope of the profiles is likely to be a signature of mixing processes. Also ozone is depleted rapidly in the MBL (below $1 \mathrm{~km}$ during this time) as a result a shift from photochemical production to destruction of ozone (as shown in Fig. 9 of (Cain et al., 2012)) associated with the higher humidity and also deposition of species to the ocean surface such as nitric acid and ozone itself (Fairall et al., 2006).

The same flight observations have been analysed by several authors. The flight tracks on 20 and 21 July are coloured by $\mathrm{CO}$ mixing ratio in Figs. $4 \mathrm{a}$ and $5 \mathrm{a}$ in Lee et al. (2011). Their analysis focuses on the evolution of an air mass they label the "New York Plume" which was characterised by the highest concentration of pollution observed on those flights. It was intercepted over Long Island at about 18:30 UTC on 


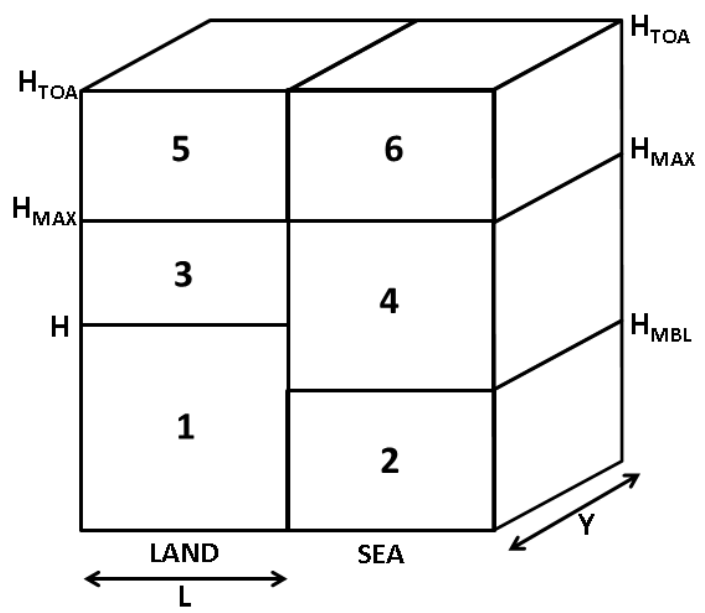

Figure 5. A schematic of the six-box partition used to analyse tracer transport in the MetUM simulation, which subsequently forms the basis of a box model. $H$ and $H_{\mathrm{MBL}}$ are the heights of the continental and marine BLs respectively. $H_{\max }$ is the maximum height of the continental $\mathrm{BL}$, defining the top of the residual layer. $H_{\mathrm{TOA}}$ represents the top of the atmosphere. Boxes 1, 3 and 5 are over land; boxes 2, 4 and 6 are over the sea. L represents the width of the domain experiencing emissions and $\mathrm{Y}$ represents the length along the coast.

20 July and at $15: 15 \mathrm{UTC}$ on 21 July around $42^{\circ} \mathrm{N}, 68^{\circ} \mathrm{W}$. The air mass examined here was located further east on both days and links with trajectories crossing the North Atlantic. The air mass was broader and related to pollution outflow from a wider area of the East Coast, rather than the tight plume related to the strong emissions in the New York area (which would not be represented in the tracer simulations). Vertical profiles of a wide range of measurements are also shown in Davis et al. (2012) from the same three flights, but the segments shown do not correspond to the Lagrangian intercepts identified by Methven et al. (2006). Consequently the time evolution is not as apparent as shown in Fig. 4.

Fang et al. (2009) present a comparison between their MOZART model simulation of $\mathrm{CO}$ and observations spanning the eastern USA by the NASA DC8 aircraft during ICARTT. The model is sampled at all the flight tracks points and both model and observations are averaged in $2 \mathrm{~km}$ altitude layers. The observed $\mathrm{CO}$ at $4 \mathrm{~km}$ across the whole region is similar to that observed on 22 July 2004 (Fig. 4b) but the regional average profile only increases to $135 \mathrm{ppbv}$ at $1 \mathrm{~km}$ (compared with 170-180 ppbv in the case shown). Therefore the pollution plume followed remains substantially elevated relative to the background $\mathrm{CO}$ throughout the 3 days. The MOZART model used by Fang et al. (2009) produced a larger contrast in $\mathrm{CO}$ than that observed between $1 \mathrm{~km}$ and $3 \mathrm{~km}$, indicating that vertical transport away from the surface in their simulation was too weak. Here, the tracer simulations also show a larger contrast, but this is partly a result of the shorter tracer lifetime.

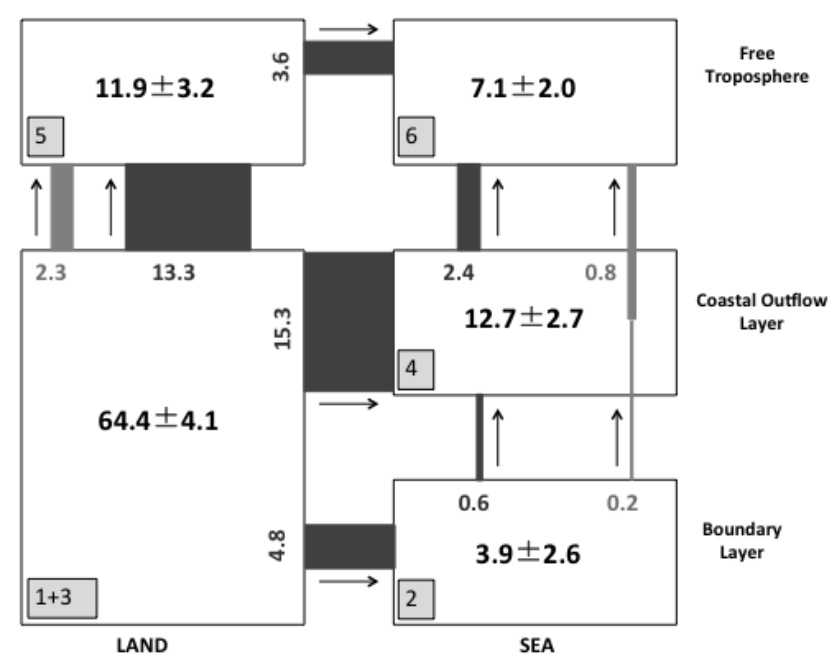

Figure 6. Schematic showing the quasi-steady-state distribution of tracer in balance between continuous emission at the land surface and uniform decay with a $24 \mathrm{~h}$ lifetime in the MetUM simulation. The continental boundary and residual layers (boxes 1 and 3) are combined into one box. Numbers in the centre of each box represent the average units of tracer residing in each box (plus/minus one standard deviation) normalised such that the total is 100 . The arrows indicate the direction of net mass transport between boxes and the numbers and width of each band represent the amount transported along the related pathway in order to maintain steady state. Light grey arrows are estimates of transport by convection, and dark grey for advection and turbulent mixing.

The ozone observations highlight the contrast between pollution export from the coast within the MBL and air immediately above. MBL air is humid and in rapid contact with the ocean surface, resulting in a much more rapid change in chemical composition (generally cleansing). In contrast, air immediately above can be transported right across ocean basins, and although air masses transform slowly through chemical reaction and mixing, they can be distinguished by their distinct hydrocarbon footprint after many days (Methven et al., 2006). The flow is also typically faster above the BL. This motivates our definition of coastal outflow in terms of the air exported from a continent, but decoupled from the surface over the ocean.

\section{MetUM tracer budget partitioned into box-model structure}

The evolution of tracer mass within in the MetUM simulation is analysed by partitioning the domain into areas over land and sea and then also in the vertical depending on BL depth (Fig. 5). The complexity of the situation simulated by the MetUM is reduced to a few variables that describe tracer amounts in these six "boxes" and the fluxes between them. In Sect. 4.1, equations will be derived for a box model that describes the evolution of the masses in each box and their de- 


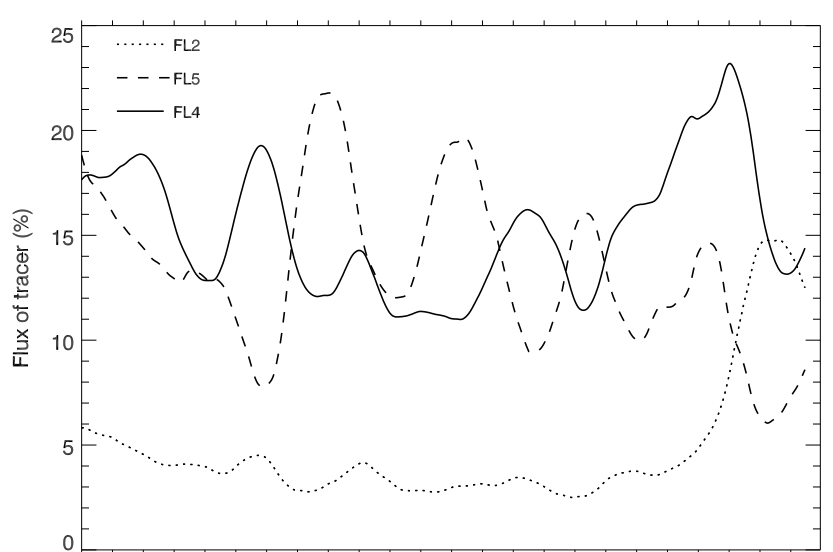

161718192021222324252627282930310102030405060708 $00 Z$ on calendar day of July/August 2004

Figure 7. $24 \mathrm{~h}$ running average time series of net tracer fluxes from the continental BL including the residual layer (boxes 1 and 3) expressed as a percentage of total tracer in the domain, assuming quasi-stationary masses. Mass transport into the MBL, $F_{L 2}$ (dotted), into the coastal outflow layer, $F_{L 4}$ (solid) and vertically into the free troposphere, $F_{L 5}$ (dashed).

pendence on a few parameters defining the problem. The Appendix gives an analytic solution to the box model in the simplest situation where the model parameters are constants. The box model represents a way of rationalising the behaviour of regional pollution concentrations and coastal outflow in a realistic model, and the fundamental parameters on which they depend.

The box model consists of three layers: the BL (box-1 and box-2), the residual layer (box-3 and box-4) and the free tropospheric layer (box-5 and box-6). One column of boxes is above the land (box-1, box-3 and box-5), the other column is above the sea (box-2, box- 4 and box-6), and the interface between the two columns lies along the coastline.

The mass of tracer in each box, $M$, is calculated for each time step. The quasi-steady state mass of tracer in each box is represented by numbers in the centre of each box in Fig. 6 . It is defined by calculating the percentage of the total domain tracer in that box at each time step, and then averaging those values over the 27 day period. The arrows indicate the direction of net transport between each box that would be necessary to maintain steady state, given that all the tracer enters the domain at the land surface, but tracer is lost everywhere at the uniform decay timescale of $24 \mathrm{~h}$. The continental BL and continental residual layers are combined (box-1 and box3) to avoid depicting the large diurnal cycle of mass transport between them. The boxes over the sea are assumed to extend sufficiently far downwind from the coast that any tracer entering these boxes decays before it can leave (i.e., no tracer outflow from the domain). By construction, the mass transports are defined such that the steady-state mass of each box is decomposed into a sum of transports in, minus the sum

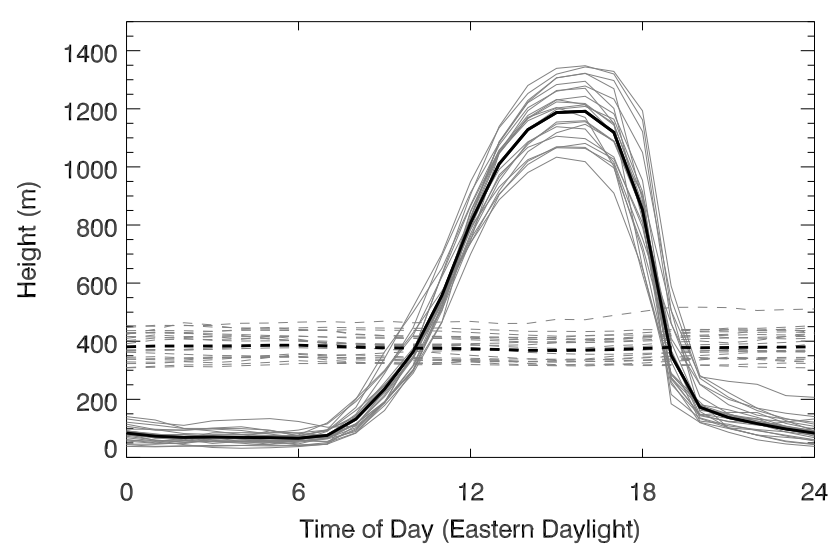

Figure 8. Diurnal cycle in BL heights averaged over the land (solid lines) and sea (dashed lines) for the MetUM simulation. Individual grey lines represent different days of the MetUM simulation; the thick black lines represent the mean BL height cycles. Time is presented with respect to Eastern Daylight Time (UTC-4).

of transports out. Note that since all emissions are into the BL over land, 100 units are emitted into this box. Deposition to the surface is not included. Therefore, it should be interpreted as depicting the various branching ratios into and out of different boxes.

To estimate the time-average transport pathways the following steps are performed. Firstly, the vertical transport of tracer by convection is calculated using the difference in the steady-state masses in the free tropospheric boxes $\left(M_{5}\right.$ and $M_{6}$ ) for two tracers: the tracer transported by all processes in the model, minus the tracer that excluded the convective transport, and 2.3 units are transported into box-5 via convection over land, while 0.8 units are transported into box- 6 via convection over the sea.

There remain seven unknown transports (the black bands in Fig. 6 plus the convective transport from the MBL) to obtain from the mass budgets of five boxes. For example, $M_{5}=F_{L 5}+C_{L 5}-F_{56}$ where $C_{L 5}$ is the convective mass transport from the continental BL to box-5 as estimated from step-1, $F_{L 5}$ is the non-convective transport from the continental BL to box-5 and $F_{56}$ is the net horizontal transport from box-5 to box- 6 . Since one of the five budget equations is not independent, due to the constraint that the box masses sum to $100 \%$, three further relations are required to solve the simultaneous equations for the seven transports:

1. Since the tracer decay rate is the same everywhere, if vertical transport over the ocean is weak, the ratio of the masses of tracer in box- 4 and box- $2, r=M_{4} / M_{2}=$ 3.33 , must equal the ratio of the horizontal fluxes into those boxes across the coast. Therefore, it is assumed that $F_{L 4} / F_{L 2}=r$.

2. Assume that the horizontal transport in the free troposphere from box -5 to box- 6 is related to the horizontal 
(a)

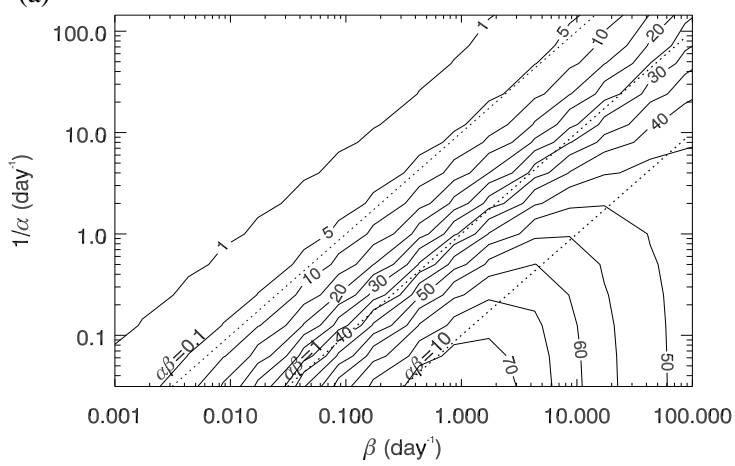

(c)

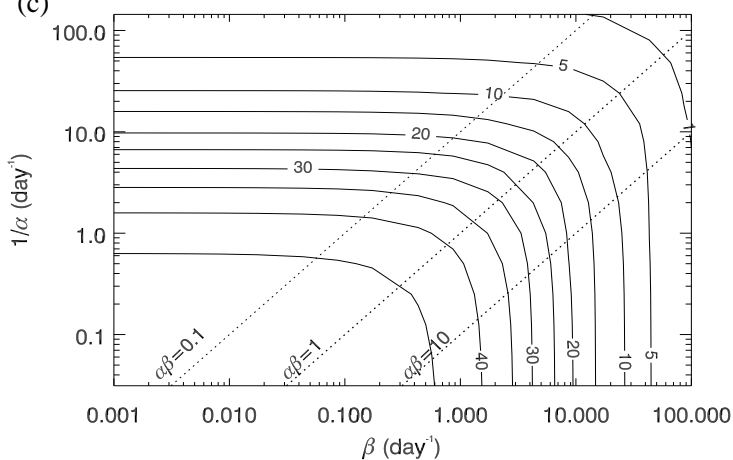

(b)

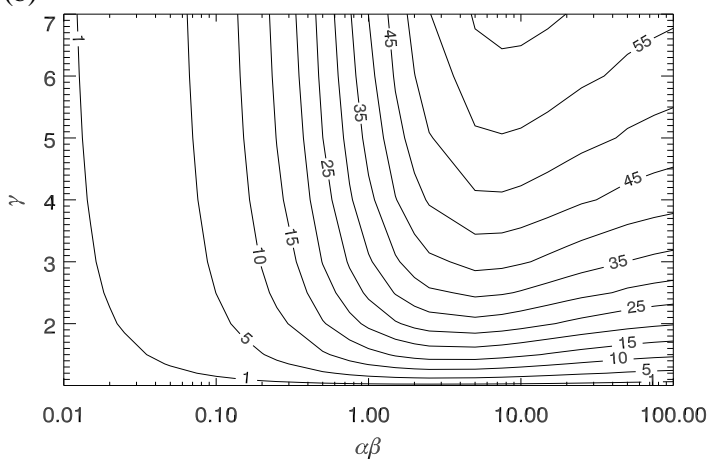

(d)

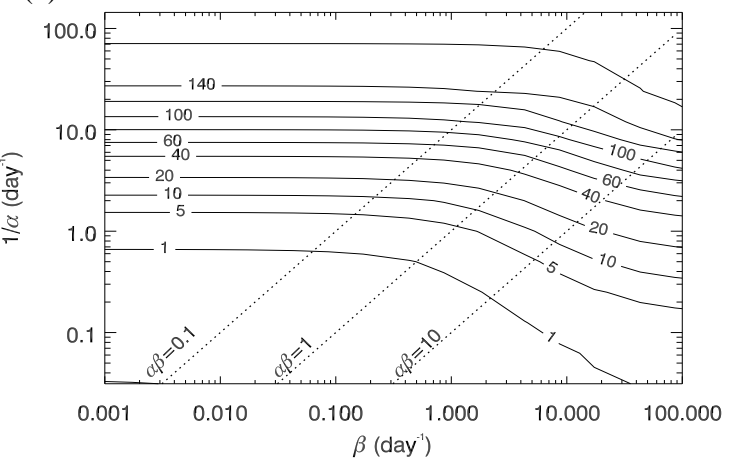

Figure 9. (a) Diurnally averaged tracer in the coastal outflow box (percentage of total domain tracer) as a function of decay rate $1 / \alpha$ and advection rate $\beta$. (b) Diurnally averaged percentage of tracer in the coastal outflow layer as a function of $\alpha \beta$ and BL-ratio $\gamma$ for $\alpha=1$ day. (c) Diurnal average of tracer in the residual layer above land $\left(M_{3} /\left(M_{1}+M_{3}\right)\right)$ as a function of $1 / \alpha$ and $\beta$. (d) Diurnal variability of tracer (diurnal range divided by diurnal mean) as a function of $1 / \alpha$ and $\beta$. In (a), (c) and (d) the BL-ratio is constant, $\gamma=5$. Long-lived tracers are represented by $\alpha \beta>10$, short-lived tracers are represented by $\alpha \beta<0.1$.

transport below by a known ratio, $R=F_{56} /\left(F_{L 2}+F_{L 4}\right)$. The simple assumption used relates $R$ to the mass of tracer available to advect horizontally from the continent $R=M_{5} / M_{L}$

3. The proportion of convective to resolved vertical transport over the sea from box-2 to box-4 is assumed to be the same as from box-4 to box- $6 ; C_{24} / F_{24}=C_{46} / F_{46}$.

These three assumptions were used to solve for the mass transport estimates in Fig. 6. The magnitude of tracer ventilated from the continental BL via coastal outflow is similar to the magnitude of tracer ventilated by vertical processes out of the continental BL (13.3 units by resolved vertical advection and mixing, 2.3 by convective mass fluxes) for the eastern half of the United States (the domain area of the MetUM simulation). The horizontal transport from land over the Atlantic is dominated by the coastal outflow layer above the MBL. In reality, soluble pollutants would also be rapidly deposited to the ocean surface from the MBL, while they would be somewhat isolated from deposition in the coastal outflow layer above.

Figure 7 shows the net tracer fluxes from the continental $\mathrm{BL}$ and residual layer (boxes 1 and 3) vertically into the region above $\left(F_{L 5}\right)$ and horizontally into the $\operatorname{MBL}\left(F_{L 2}\right)$ and

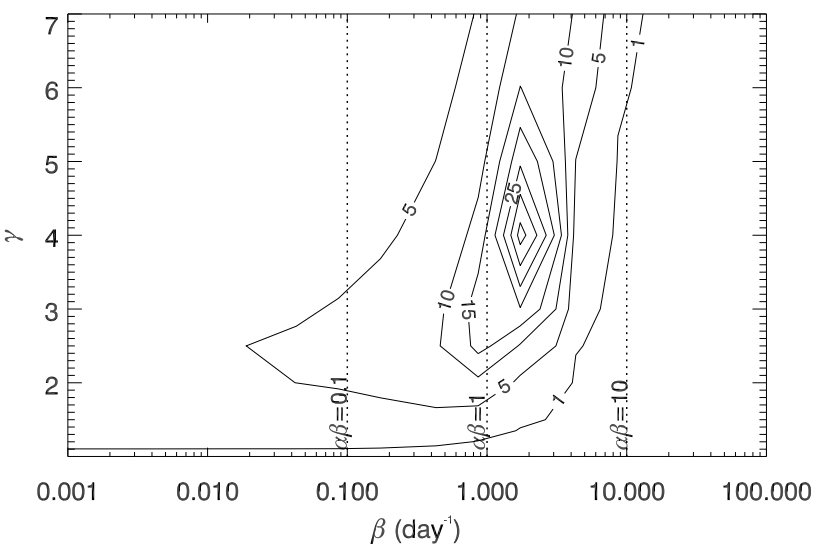

Figure 10. Correlation between the diurnal cycles of percentage of tracer in the coastal outflow layer in the MetUM simulation and box model divided by the root mean square difference between the diurnal cycles. Tracer has $24 \mathrm{~h}$ lifetime. The maximum indicates best parameter fit maximising correlation/bias.

coastal outflow layer $\left(F_{L 4}\right)$. The estimates are obtained at each time from the box masses by solving the simultaneous equations described above, assuming a quasi-stationary 


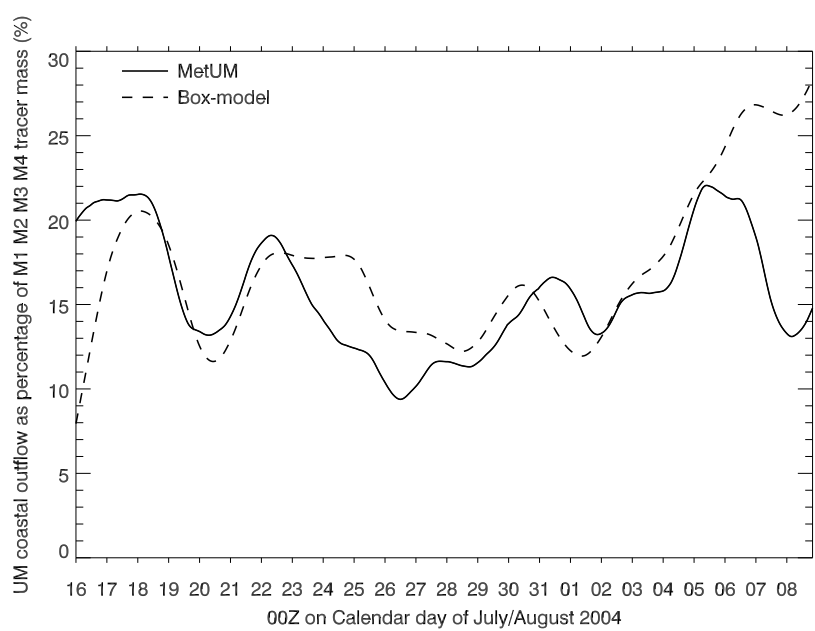

Figure 11. Time series of tracer in the coastal outflow layer as a percentage of $M_{1}+M_{2}+M_{3}+M_{4}$. Comparing the MetUM simulation (solid line) and box model (dashed line) forced with the cross-coastal wind speeds at $850 \mathrm{hPa}$ obtained by averaging along the coast and filtering out the diurnal cycle.

state. The transport into the MBL is the smallest term and least variable, with the exception of the last few days when the MBL was considerably deeper than usual. Flux into the coastal outflow layer varies substantially about the mean of 15.3 units and builds during the early days of August. The final drop reflects the increase in MBL height. Throughout July there is an anticorrelation between coastal outflow and vertical ventilation of the continental $\mathrm{BL}$, reflecting availability of tracer in the residual layer for transport via either pathway.

\section{Characterising the problem using a time-dependent box model}

\subsection{Box-model evolution equations}

A box model is now developed to describe the evolution of tracer amounts in the layers above the land and sea introduced in the previous section. The aim is to reduce the complexity of the air pollution problem to a simple system described by a few fundamental parameters that can be estimated from data. The behaviour of the reduced system is explored and related to the mesoscale model and atmospheric composition observations.

As with the mesoscale model simulation, pollution is modelled within the box model using a passive tracer with efolding lifetime $\alpha$. Tracer is emitted at a constant rate in the lowest box over land only (box-1) as a representation of anthropogenic emissions. Tracer mixing ratio and air density are assumed to be well mixed within each box at any instant.

The horizontal wind, $U$, advecting tracer from land to sea is assumed to be eastwards $(U>0)$ and uniform in height and time. There is no vertical advection between boxes. However, transport between the BL and residual layer occurs via entrainment and detrainment as the BL top over land moves up and down with the diurnal cycle.

The boxes over the sea are assumed to extend sufficiently far downwind from the coast that any tracer entering these boxes decays before it can leave (i.e., no outflow). The width of the land boxes $(L)$ is an important parameter of the model. This is because the horizontal inflow into the continental boxes from the west is assumed to carry no tracer and therefore $L$ determines the width of the domain experiencing emissions and therefore the total tracer into the model. In the parameter studies, $L$ is varied between $100 \mathrm{~m}$ and $10000 \mathrm{~km}$ to represent emissions along a narrow coastal strip to an entire continent.

Based on diagnosis of $H$ and $H_{\mathrm{MBL}}$ from the MetUM simulation (Fig. 8), $H_{\mathrm{MBL}}$ in the box model is held constant and $H$ varies sinusoidally between a maximum, $H_{\max }$, at 3 p.m. LT and a minimum $(50 \mathrm{~m})$ at $3 \mathrm{a} . \mathrm{m}$. LT. The residual layer extends from the top of the MBL or continental BL ( $H_{\mathrm{MBL}}$ and $H$ respectively) to the maximum height of the continental BL $\left(H_{\max }\right)$ as described earlier. The residual layer represents the layer of air between the current BL height and the maximum height through which pollution could have been turbulently mixed on previous days. Coastal outflow in the box model, i.e. horizontal advection across the coast between $H_{\mathrm{MBL}}$ and $H_{\max }$ is represented by tracer transport into box-4.

The equations governing the rate of change of tracer mass $M_{1}$ to $M_{6}$ in each of the boxes are derived from integrating the general tracer conservation equation:

$\frac{\partial(\rho q)}{\partial t}+\nabla \cdot(\rho q \boldsymbol{u})=\rho s-\frac{\rho q}{\alpha}$,

where $q$ is tracer mixing ratio, $\rho$ is air density, $t$ is time, $\mathbf{u}$ is the 3-D wind vector, $s$ represents sources (per unit mass) and $\alpha$ is a loss timescale. Integrating over an arbitrary volume and using Gauss' theorem gives:

$$
\begin{aligned}
& \frac{\mathrm{d}}{\mathrm{d} t} \iiint \rho q \mathrm{~d} V+\iint \rho q\left(\boldsymbol{u}-\boldsymbol{u}_{\mathrm{b}}\right) \cdot \boldsymbol{n} \mathrm{d} S \\
& =\iiint \rho\left(s-\frac{q}{\alpha}\right) \mathrm{d} V,
\end{aligned}
$$

where $\boldsymbol{u}_{\mathrm{b}}$ is the velocity of the boundary of the volume and $\boldsymbol{n}$ is the outward pointing normal to the boundary. Now assume without loss of generality that the volume is a cuboid with length $Y$ along the coast, with depth $H$ and width $L$ in the cross-coastal direction. Further assume that the lateral boundaries do not move $\left(\boldsymbol{u}_{\mathrm{b}}=0\right)$, but the top boundary can 
move. It can then be shown that:

$$
\begin{aligned}
& \frac{\mathrm{d} M}{\mathrm{~d} t}=\langle\rho q u\rangle_{\text {in }} Y H-\langle\rho q u\rangle_{\text {out }} Y H \\
& +\left[\rho q \frac{\mathrm{d} H}{\mathrm{~d} t}\right] L Y+S-\frac{M}{\alpha},
\end{aligned}
$$

where $M$ is the total tracer mass in the box, the anglebrackets represent averages across the inflow and outflow lateral boundaries of the box and the square brackets denote an average across the top boundary. Note that only the crosscoastal component of the flow has been included for simplicity, but the other components could readily be included. $\mathrm{d} H / \mathrm{d} t$ is the rate of movement of the box top and $S$ is the box-integrated source rate. This expression is exact and depends only on the definition of the volumes and tracer conservation.

Now some simplifying assumptions are made. The horizontal velocity is assumed to be uniform and the tracer mixing ratio and density at an outflow boundary are assumed to equal the average throughout the box, $\langle\rho q\rangle$. Therefore,

$\langle\rho q u\rangle_{\mathrm{out}} Y H=U\langle\rho q\rangle Y H=\frac{U}{L} M$,

using $M=\langle\rho q\rangle L Y H$. Now consider box-1 describing the continental BL where $M_{1}=\langle\rho q\rangle_{1} L Y H$ and $H$ is BL height. The tracer inflow is assumed to be zero. If the BL top is descending it is assumed that air from the BL is continuously redefined as residual-layer air and has the mixing ratio and density of the average within the BL. Conversely, if the BL top is ascending it is assumed that the BL entrains air with the current mixing ratio and density of the residual layer, $\langle\rho q\rangle_{3}$. Using (3) and $M_{3}=\langle\rho q\rangle_{3} L Y\left(H_{\max }-H\right)$ and introducing the normalised BL height $h=H / H_{\max }$ where $0<h<1$, the net result for the evolution of mass in box-1 can be written:

$$
\frac{\mathrm{d} M_{1}}{\mathrm{~d} t}= \begin{cases}S-\left(\frac{1}{\alpha}\right) M_{1}-\beta M_{1}+\frac{1}{1-h}\left(\frac{\mathrm{d} h}{\mathrm{~d} t}\right) M_{3} ; & \mathrm{d} H / \mathrm{d} t \geq 0 \\ S-\left(\frac{1}{\alpha}\right) M_{1}-\beta M_{1}+\frac{1}{h}\left(\frac{\mathrm{d} h}{\mathrm{~d} t}\right) M_{1} ; & \mathrm{d} H / \mathrm{d} t<0,\end{cases}
$$

where the advection rate $\beta=U / L$. Similarly for the other two boxes over land we find:

$$
\begin{aligned}
& \frac{\mathrm{d} M_{3}}{\mathrm{~d} t}= \begin{cases}-\left(\frac{1}{\alpha}\right) M_{3}-\beta M_{3}-\frac{1}{1-h}\left(\frac{\mathrm{d} h}{\mathrm{~d} t}\right) M_{3} ; & \mathrm{d} H / \mathrm{d} t \geq 0 \\
-\left(\frac{1}{\alpha}\right) M_{3}-\beta M_{3}-\frac{1}{h}\left(\frac{\mathrm{d} h}{\mathrm{~d} t}\right) M_{1} ; & \mathrm{d} H / \mathrm{d} t<0\end{cases} \\
& \frac{\mathrm{d} M_{5}}{\mathrm{~d} t}=-\left(\frac{1}{\alpha}\right) M_{5}-\beta M_{5} .
\end{aligned}
$$

The tracer mass crossing the coast into the coastal outflow layer and MBL depends on the ratio of the height of the residual layer to the MBL height, $\gamma=H_{\max } / H_{\mathrm{MBL}}$, typically greater than 1 . In addition, since the mixing ratio in the continental BL (box-1) is generally greater than in the residual layer above it (box-3), another important parameter is the normalised BL height, $h$. The outgoing tracer from boxes 2 and 4 is assumed to be zero (i.e., it decays before it can leave by advection). The resulting equations for the boxes over ocean are:

$\frac{\mathrm{d} M_{2}}{\mathrm{~d} t}= \begin{cases}-\left(\frac{1}{\alpha}\right) M_{2}+\left(\frac{1}{\gamma h}\right) \beta M_{1} ; & H \geq H_{\mathrm{MBL}} \\ -\left(\frac{1}{\alpha}\right) M_{2}+\beta M_{1}+\left(\frac{1-\gamma h}{\gamma-\gamma h}\right) \beta M_{3} ; & H<H_{\mathrm{MBL}}\end{cases}$

$\frac{\mathrm{d} M_{4}}{\mathrm{~d} t}= \begin{cases}-\left(\frac{1}{\alpha}\right) M_{4}+\left(1-\frac{1}{\gamma h}\right) \beta M_{1}+\beta M_{3} ; & H \geq H_{\mathrm{MBL}} \\ -\left(\frac{1}{\alpha}\right) M_{4}+\left(\frac{\gamma-1}{\gamma-\gamma h}\right) \beta M_{3} ; & H<H_{\mathrm{MBL}}\end{cases}$

$\frac{\mathrm{d} M_{6}}{\mathrm{~d} t}=-\left(\frac{1}{\alpha}\right) M_{6}+\beta M_{5}$.

Equations (5) to (10) are six coupled ordinary differential equations. The continental $\mathrm{BL}$ height, $H$, is prescribed as a sinusoidally varying function. This introduces switches into the equations due to the conditional statements, making them nonlinear. If the parameters $\alpha, \beta, H_{\max }, \gamma$ and $S$ are all taken as constants, an analytic solution is possible, as shown in the Appendix. However, since time varying winds $(\beta)$ will be used as input, the results presented in all plots were obtained using numerical integration with a simple finite difference scheme with $600 \mathrm{~s}$ timestep (but the results are not sensitive to the scheme chosen). The model is initialised with zero tracer. The source rate of tracer was arbitrarily chosen as unity, as the tracer mass in each box simply scales with $\alpha S$ (see Appendix).

There are 3 timescales in the problem: the length of day (controlling variation in $h$ ), $\alpha$ and $1 / \beta$. The second is used to scale the time dimension, leaving only three non-dimensional parameters plus the sinusoidally varying non-dimensional BL height, $h$, controlling the solutions (see Appendix for details). In the following exploration of outflow regimes, the parameters are varied as follows:

- e-folding tracer lifetime, $\alpha: \alpha$ is varied between $600 \mathrm{~s}$ and 32 days, representing a wide range of potential airborne pollutant lifetimes.

- Advection rate, $\beta: \beta=U / L$, where $U$ is the wind speed $\left(\mathrm{ms}^{-1}\right)$ and $L$ is the land width $(m)$. The advection rate is proportional to the mass of tracer advected horizontally from the land to sea boxes per second. $\beta$ is varied from $10^{-3}$ day $^{-1}$ (e.g., $U=0.1 \mathrm{~ms}^{-1}$ and $L=10000 \mathrm{~km}$ ) to $100 \mathrm{day}^{-1}$ (e.g., $U=10 \mathrm{~ms}^{-1}$ and $L=100 \mathrm{~m}$ ).

- BL ratio, $\gamma: \gamma=H_{\max } / H_{\mathrm{MBL}}$ is the ratio between the maximum continental BL height and the MBL height. If $\gamma=1$ then there is no coastal outflow layer. In the MetUM simulation, the parameters $H_{\max }$ and $H_{\mathrm{MBL}}$ did not vary greatly and $\gamma \approx 5$. In the parameter study, $\gamma$ is varied from 1 to 7 based on observations from studies that observed typical MBL depths of up to 250 to $750 \mathrm{~m}$ in the Gulf of Maine (Angevine et al., 2006; Wolfe et al., 2007). 
An important combination of parameters $\alpha \beta$ describes the decay rate of tracers relative to the advection rate and has a major influence on the solutions. When $\alpha \beta=1$, tracer decay and advection rates are equal, thus it takes one tracer lifetime for tracer to be advected a distance equal to one land width. When $\alpha \beta>10$, the tracer is long-lived relative to the advection timescale. When $\alpha \beta<0.1$, the tracer is described as short-lived.

\subsection{Exploring parameter regimes of coastal outflow}

Figure 9a shows the diurnally averaged tracer amount (as the proportion of total domain tracer) within the coastal outflow box (box-4) as a function of tracer decay rate and advection rate using a constant BL-ratio $\gamma=5$. As the decay rate $\left(\alpha^{-1}\right)$ decreases the proportion of tracer in the coastal outflow layer increases. The increased lifetime of the tracer enables it to undergo greater horizontal advection before it decays to small values, and thus has greater potential to be exported across the coast. Decreasing the decay rate by three orders of magnitude increases the percentage of tracer in the coastal outflow box from $1 \%$ to $70 \%$ (for a fixed advection rate of 1 day $^{-1}$ ).

As the advection rate increases (for $\alpha \beta<10$ ) the proportion of tracer undergoing coastal outflow also increases, consistent with the idea that a greater cross-coastal wind speed allows greater advection and thus greater tracer export across the coast. However, in the long-lived regime $(\alpha \beta>10)$ increasing advection rate results in a decrease in coastal outflow. This occurs because the advection rate is so large that tracer advected horizontally out of the continental residual layer during the night-time, is not replenished in the residual layer until the $H$ increases in depth the next day. This reduces the availability of tracer available to undergo coastal outflow. The dependence on day length is most obvious for the tracers with slowest decay rate, where the maximum in the outflow layer occurs for an advection rate of $1 \mathrm{day}^{-1}$. For tracers with faster decay, the maximum occurs for $\alpha \beta \approx 10$.

The variation of the diurnally averaged proportion of tracer in the coastal outflow layer with changes in $\alpha \beta$ and $\gamma$ is shown in Fig. 9b. For long-lived tracers $(\alpha \beta>1)$ the proportion of tracer undergoing coastal outflow depends on the BLratio, $\gamma$, and this dependence is much weaker for short-lived tracers. As $\gamma$ increases, the proportion of tracer in the coastal outflow layer increases due to the change in proportion of time that $H>H_{\mathrm{MBL}}$ in the box model. However, given the relatively small range of BL-ratio $(3<\gamma<6)$ exhibited in the MetUM simulation, and the small impact that variation in BL-ratio produces in coastal outflow, it can be concluded that synoptic variations in BL-ratio are relatively unimportant in determining the day-to-day variability in coastal outflow amount.

The mass of tracer in the continental residual tracer, as a proportion of all tracer over the land (i.e. $M_{3} /\left(M_{1}+M_{3}\right)$ ), is shown in Fig. 9c for $\gamma=5$. The maximum percentage of tracer in the continental residual layer is $50 \%$ in the diurnal average due to the sinusoidal variation in $H$ between $50 \mathrm{~m}$ $(h \approx 0)$ and $H=H_{\max }(h=1)$ within the box model. For short-lived tracers $(\alpha \beta<0.1)$ the proportion of mass within the continental residual layer is dependent only on the tracer decay rate, with less surviving in the residual layer for faster decay. For long-lived tracers $(\alpha \beta>10)$ the proportion within the continental residual layer is dependent only on the advection rate; increasing the advection rate depletes the proportion of long-lived tracer over land within the continental residual layer and causes the subsequent reduction of coastal outflow, which can also be seen in Fig. 9a and b.

The diurnal variability of tracer in the coastal outflow box is defined as the range over $24 \mathrm{~h}$ divided by its diurnal average. Figure $9 \mathrm{~d}$ shows the diurnal variability for a BL-ratio of $\gamma=5$. For short-lived tracers $(\alpha \beta<0.1)$ the diurnal variability is independent of the advection rate and entirely dependent on the lifetime of the tracer. As the lifetime of the tracer increases, the diurnal variability decreases. For example, a tracer with a 1 day lifetime has a diurnal variability of $3 \%$ about its mean value of coastal outflow tracer percentage, caused by the variation in $\mathrm{H}$. For long-lived tracers $(\alpha \beta>1)$, the advection rate also affects the diurnal variability of tracer in the coastal outflow layer. An increase in the advection rate causes increases in the diurnal variability of coastal outflow as the availability of tracer decreases.

\section{Understanding observed tracer evolution using the box model}

For a short-lived pollutant $(\alpha \beta \ll 1)$, it is reasonable to assume it must be emitted close to the coastline to enable it to undergo coastal outflow before it decays to very small concentrations. Likewise, for a long-lived pollutant $(\alpha \beta \gg 1)$, it can be emitted further inland and still undergo coastal outflow. In addition, we might expect that the average diurnal variability of tracer in the coastal outflow layer is influenced by emissions within a short transport range of the coast, while longer timescale variations could be affected by transport from further afield. We introduce the concept of a representative land width as the width of the coastal strip with emissions (assumed uniform) that best explains the observed variability of coastal outflow using the box model. Implicitly it is assumed that the approximations leading to the boxmodel reduction are to some extent valid.

\subsection{Representing diurnal variability}

One way to examine the representative land width over which emissions influence coastal outflow is to examine the average diurnal variability of tracer in the coastal outflow layer. The diurnal cycles in percentage of tracer in the coastal outflow layer (box-4) are compared from the MetUM simulation and the box model. Model parameters are varied and the 
maximum correspondence between the average diurnal cycle in the two models is sought. We require that the cycle in the box model is well correlated with the realistic simulation, but also obtains similar magnitude of variation such that the rms difference between the models is small. A sensitive diagnostic is to calculate the correlation divided by the rms difference, as shown in Fig. 10 for a fixed tracer lifetime of 1 day. A maximum in correlation divided by difference occurs at $\beta=2$ day $^{-1}$. Thus, given an average $850 \mathrm{hPa}$ cross-coastal wind speed of $U=2.14 \mathrm{~m} \mathrm{~s}^{-1}$ (based on the MetUM simulation), the representative land width, $L=U / \beta$ is approximately $100 \mathrm{~km}$. Note that the diurnal cycle is relatively insensitive to $\gamma$, but the best fit is obtained when using $\gamma=4$ which is close to the value obtained from the BL in the mesoscale model.

\subsection{Representing day-to-day variability}

An alternative method for estimating the representative land width is to compare longer timescale variability in the tracer mass in the coastal outflow layer predicted by the simple box model with the time series calculated from the realistic mesoscale model simulation. In particular, the diurnal cycle has been filtered out to focus on synoptic timescale variability. In order to carry out this comparison it is necessary to force the box model using the time varying cross-coastal wind speed from the MetUM simulation. The cross-coastal wind speed was calculated along a smoothed representation of the coastline with an average offshore normal orientation of $120^{\circ}$ relative to grid North. The $850 \mathrm{hPa}$ pressure level occurs at a height within the coastal outflow layer based on the BL heights calculated from the MetUM. The $850 \mathrm{hPa}$ cross-coastal wind speed is on average $U=2.14 \mathrm{~m} \mathrm{~s}^{-1}$. A running median filter with $24 \mathrm{~h}$ window is used to remove the diurnal cycle from the hourly mesoscale model output. The standard deviation of the cross-coastal time-filtered winds is $\sigma=1.49 \mathrm{~m} \mathrm{~s}^{-1}$.

The filtered time series of cross-coastal wind was fed into the box model run using fixed parameters $\alpha=1$ day, $\gamma=5$ and a value for land width, $L$, used to find $\beta=U / L$. The resulting output was also passed through the $24 \mathrm{~h}$ filter. The box model was re-run with different values of $L$. This fixes the width of the domain experiencing emissions. The amount of tracer in the coastal outflow box $\left(M_{4}\right)$ depends on the amount of tracer over land $\left(M_{L}\right)$, which in turn depends on $L$ (Eqs. 59 ). We find that a land width of approximately $400 \mathrm{~km}$ gives box-model results that match the MetUM simulation most closely. Figure 11 shows $24 \mathrm{~h}$ running averages of coastal outflow from both models. The box model is able to capture the major episodes of coastal outflow, with the proportion of tracer in the coastal outflow exhibiting a similar variation to that shown in the MetUM. Furthermore, the shape of the time series is similar to the time series of $\mathrm{CO}$ flux through the northeast boundary in the MOZART simulation of Fang et al. (2009) (their Fig. 3), illustrating that variability in the tracer has relevance to the variability in pollution across the region. The correlation between the percentage of tracer in the coastal outflow box in the MetUM and box-model simulations is +0.69 , which implies that the variability in the cross-coastal wind speed accounts for $48 \%$ of the variance in coastal outflow. For some periods, the box model does not capture the variability in MetUM simulated coastal outflow. This is likely to be due to weak synoptically forced situations when mesoscale circulations, such as shallow convection and sea breeze circulations, can ventilate tracer from the continental BL. These mesoscale circulations are not represented in the box model, but are represented in the MetUM as discussed in Sect. 2.

\section{Conclusions}

In this paper the magnitude and variability of coastal outflow are quantified using the MetUM mesoscale model and interpreted using a simple box-model framework. The MetUM showed that over a 4 week period in summer 2004, horizontal ventilation of the continental BL by coastal outflow was similar in magnitude to vertical ventilation when a domain covering the eastern USA was considered.

The regional tracer mass budget was reduced to a box model describing coastal outflow using only three parameters; the tracer lifetime, cross-coastal wind speed, and ratio $H_{\max } / H_{\mathrm{MBL}}$. The least important parameter influencing the variability of tracer in the coastal outflow layer from day to day was $H_{\max } / H_{\mathrm{MBL}}$.

A non-dimensional ratio $(\alpha \beta)$ is defined by dividing the advection rate by the decay rate. Short-lived $(\alpha \beta<0.1)$ and long-lived $(\alpha \beta>10)$ tracers exhibit different coastal outflow dependencies. For short-lived tracers, increasing the advection rate increases the magnitude of coastal outflow. For long-lived tracers, increasing the advection rate decreases the magnitude of coastal outflow, due to reduced availability of tracer in the residual layer.

It is argued that the parameter values from the simple box model that obtain the best fit relative to the mesoscale model simulation are relevant to the transport regime across the eastern USA. In particular, if the wind field for the period, tracer lifetime and ratio $H_{\max } / H_{\mathrm{MBL}}$ are taken as given, the only free parameter is the representative land width which relates the average cross coastal wind speed to a tracer advection rate, $\beta$. One interpretation of the land width is that it is the width of the coastal strip where emissions have an influence on coastal outflow (for a given tracer lifetime). It was obtained as the length scale that best explains variability in the pollutant loading in the coastal outflow layer. When considering the composite diurnal cycle a relatively short land width of $100-200 \mathrm{~km}$ was found to be capable of explaining the average range of the diurnal variation. However, for synoptic timescale variability (after applying a running mean filter with $24 \mathrm{~h}$ window) a land width of $400 \mathrm{~km}$ was found 
to describe best the observed variability. The results imply that coastal outflow has a strong influence on regional pollution across the region for a considerable distance inland from the coast. Although not represented in the tracer simulations, the eastern USA also has a much greater population density along the coastal strip and anthropogenic emissions. This could only act to increase the influence of coastal outflow on the air quality of the region. 


\section{Appendix A: Analytical solutions for the box model}

The box-model equations (5) to (10) can be solved analytically if the parameters $\alpha, \beta, H_{\max }, \gamma$ and $S$ are all taken as constant. In doing so, it is most convenient to recast them in the non-dimensional form:

$$
\begin{aligned}
& \dot{m}_{1}= \begin{cases}1-(1+\lambda) m_{1}+\frac{\dot{h}}{1-h} m_{3} & \dot{h} \geq 0 \\
1-\left(1+\lambda-\frac{\dot{h}}{h}\right) m_{1} & \dot{h}<0\end{cases} \\
& \dot{m}_{3}= \begin{cases}-\left(1+\lambda+\frac{\dot{h}}{1-h}\right) m_{3} & \dot{h} \geq 0 \\
-(1+\lambda) m_{3}-\left(\frac{\dot{h}}{h}\right) m_{1} & \dot{h}<0\end{cases} \\
& \dot{m}_{2}= \begin{cases}-m_{2}+\lambda\left(\frac{h_{m}}{h}\right) m_{1} & h \geq h_{m} \\
-m_{2}+\lambda m_{1}+\lambda\left(\frac{h_{m}-h}{1-h}\right) m_{3} & h<h_{m}\end{cases} \\
& \dot{m}_{4}= \begin{cases}-m_{4}+\lambda\left(1-\frac{h_{m}}{h}\right) m_{1}+\lambda m_{3} & h \geq h_{m} \\
-m_{4}+\lambda\left(\frac{1-h_{m}}{1-h}\right) m_{3} & h<h_{m}\end{cases} \\
& \dot{m}_{5}=-(1+\lambda) m_{5} \\
& \dot{m}_{6}=-m_{6}+\lambda m_{5} .
\end{aligned}
$$

In Eqs. (A1) to (A6) time, length and mass have been non-dimensionalised so that $\hat{t}=t / \alpha, h=H / H_{\max }, m_{i}=$ $M_{i} /(\alpha S)$ and $\dot{m}_{1}$ denotes the derivative with respect to $\hat{t}$ and so on. There are then only two constant non-dimensional parameters $\lambda \equiv \alpha \beta$ and $h_{m} \equiv H_{\mathrm{MBL}} / H_{\max } \equiv 1 / \gamma$ plus the sinusoidally varying BL height, $h$. Note that in this particular scaling of time, the length of day $\hat{t}_{d}=t_{d} / \alpha$ where $t_{d}$ is the dimensional day length. $\hat{t}_{d}$ is a third parameter that implicitly influences the solution via the diurnal variation of $h$.

These coupled first order ODEs can be solved by judicious inspection of the nature of the coupling and the conditional switches. The equation for $m_{5}$ is decoupled from the rest of the system and so $m_{5}$ can be easily solved first. The solution can then be plugged into the last equation to solve for $m_{6}$ :

$$
\begin{aligned}
& m_{5}(t)=m_{5}(0) e^{-(1+\lambda) t} \\
& m_{6}(t)=m_{6}(0) e^{-t}+m_{5}(0) e^{-t}\left(1-e^{-\lambda t}\right) .
\end{aligned}
$$

With the specified initial conditions, $m_{i}(t)=0, \forall i$, we get $m_{5}(t)=m_{6}(t)=0, \forall t$; hence, boxes 5 and 6 play no role and we effectively have a four-box model.

The equations for $m_{1}$ and $m_{3}$ are coupled to each other, and those for $m_{2}$ and $m_{4}$ are mutually coupled as well as to those for $m_{1}$ and $m_{3}$. Hence, it is sensible to solve for $m_{1}$ and $m_{3}$ first, followed by $m_{2}$ and $m_{4}$. Three unconditional equations can be obtained by adding the above equations for the total mass $m=m_{1}+m_{2}+m_{3}+m_{4}+m_{5}+m_{6}$, the sum of the mass in boxes 1 and $3, m_{13} \equiv m_{1}+m_{3}$ and the sum of mass in boxes 2 and $4, m_{24} \equiv m_{2}+m_{4}$ :

$\dot{m}=1-m$

$\dot{m}_{13}=1-(1+\lambda) m_{13}$ $\dot{m}_{24}=-m_{24}+\lambda m_{13}$

The solution of Eq. (A9) for the total mass is

$m(t)=m(0) e^{-t}+\left(1-e^{-t}\right)$.

This solution shows that, irrespective of the initial mass $m(0)$ in the system, the steady state mass is given by $m(\infty)=1$, i.e. $M(\infty)=\alpha S$, the amount of material emitted in a time equal to the tracer lifetime $\alpha$, and is independent of $\beta$.

Equation A10 integrates to give:

$m_{13}(t)=m_{13}(0) e^{-(1+\lambda) t}+\frac{1}{1+\lambda}\left(1-e^{-(1+\lambda) t}\right)$,

which can be used with Eq. (A11) to give

$$
\begin{aligned}
m_{24}(t)= & +\left(m_{13}(0)-\frac{1}{1+\lambda}\right)\left(e^{-t}-e^{-(1+\lambda) t}\right) \\
& +\frac{\lambda}{1+\lambda}\left(1-e^{-t}\right)
\end{aligned}
$$

In the asymptotic limit $t \rightarrow \infty$ we find that $m_{13}(\infty)=$ $1 /(1+\lambda)$ and $m_{24}(\infty)=\lambda /(1+\lambda)$, so that the proportion of mass over sea is a factor of $\alpha \beta$ times that over land at steady state.

The above solutions hold for all time $t$. The individual form of the solutions for $m_{1}$ and $m_{3}$ will depend on the sign of $\dot{h}$ and, for $m_{2}$ and $m_{4}$, additionally on the sign of $h-h_{m}$. The solutions for $m_{1}$ and $m_{3}$ are given by

$$
m_{1}(t)=\left\{\begin{array}{rr}
m_{1}(0) e^{-(1+\lambda) t} & \\
+m_{3}(0) \frac{h(t)-h(0)}{1-h(0)} e^{-(1+\lambda) t} & \\
+\frac{1}{1+\lambda}\left[1-e^{-(1+\lambda) t}\right], & \dot{h} \geq 0 \\
m_{1}(0) \frac{h(t)}{h(0)} e^{-(1+\lambda) t} & \\
+h(t) \int_{0}^{t} \frac{e^{(1+\lambda)(s-t)}}{h(s)} d s, & \dot{h}<0
\end{array}\right.
$$

$$
m_{3}(t)=\left\{\begin{array}{rr}
m_{3}(0) \frac{h(t)-1}{h(0)-1} e^{-(1+\lambda) t}, & \dot{h} \geq 0 \\
+m_{3}(0) \frac{h(0)-h(t)}{h(0)} e^{-(1+\lambda) t} & \\
+\frac{1}{1+\lambda}\left[1-e^{-(1+\lambda) t}\right] & \\
-h(t) \int_{0}^{t} \frac{e^{(1+\lambda)(s-t)}}{h(s)} d s, & \dot{h}<0
\end{array}\right.
$$

Note that here the zero point of time is taken as the last time switching between $\dot{h} \geq 0$ and $\dot{h}<0$ occurred, so that $m_{1}(0), m_{3}(0)$ and $h(0)$ each refer to the end value obtained from the previous solution interval. The residual integral in equation A15 and A16 can be computed numerically for 
known $h(t)$. Assuming a sinusoidally varying BL height, we may write $h(t)=\epsilon \sin (\omega t)+(1-\epsilon)$, where $\epsilon=\left(1-h_{\text {min }}\right) / 2$, $\omega=2 \pi / \hat{t}_{d}$ and $\hat{t}_{d}=t_{d} / \alpha$, where $t_{d}$ is the length of day.

From Eqs. A 3 and A4 the solutions for $m_{2}$ and $m_{4}$ can be written formally as

$m_{2}=m_{2}(0) e^{-t}+\lambda h_{m} \int_{0}^{t} \frac{e^{s-t} m_{1}(s)}{h(s)} \mathrm{d} s \quad h \geq h_{m}$

$m_{4}=m_{4}(0) e^{-t}+\lambda\left(1-h_{m}\right) \int_{0}^{t} \frac{e^{s-t} m_{3}(s)}{1-h(s)} \mathrm{d} s \quad h<h_{m}$

(A18) with the corresponding solutions of $m_{2}$ for $h<h_{m}$ and $m_{4}$ for $h \geq h_{m}$ obtained by subtraction from the solution of $m_{24}$, Eq. A14. Substitution of the solutions for $m_{1}$ and $m_{3}$ into Eqs. A17 and A18 includes terms with residual integrals that cannot be evaluated explicitly but that can be readily computed by numerical quadrature, e.g. using Simpson's rule. 
Acknowledgements. The authors would like to thank the Met Office for use of its Unified Model and Willie McGinty for his help running the Unified Model. We also thank Bob Plant, Janet Barlow, Sue Gray and Jane Lewis for useful comments on this work. Dan Peake was supported by a NERC PhD studentship. The NOAA-DOE radar wind profiler data were obtained via the NOAA ESRL (Earth System Research Laboratory) database (http://www.esrl.noaa.gov/psd/data/obs/datadisplay/). The authors would like to thank the team who made the measurements from the NOAA WP-3D during the ICARTT experiment. Omduth Coceal gratefully acknowledges funding from NERC through the National Centre for Atmospheric Science (NCAS) under grant no. R8/H12/83/002.

Edited by: G. Vaughan

\section{References}

Angevine, W. M., Hare, J. E., Fairall, C. W., Wolfe, D. E., Hill, R. J., Brewer, W. A., and White, A. B.: Structure and formation of the highly stable marine boundary layer over the Gulf of Maine, J. Geophys. Res., 111, doi:10.1029/2006JD007465, 2006.

Cain, M., Methven, J., and Highwood, E. J.: Quantification of chemical and physical processes influencing ozone during long-range transport using a trajectory ensemble, Atmos. Chem. Phys., 12, 7015-7039, doi:10.5194/acp-12-7015-2012, 2012.

Carter, D. A., Gage, K. S., Ecklund, W. L., Angevine, W. M., Johnston, P. E., Riddle, A. C., Wilson, J., and Williams, C. R.: Developments in UHF lower tropospheric wind profiling technology at NOAA's Aeronomy Laboratory, Radio Sci., 30, 997-1001, 1995.

Dacre, H. F., Gray, S. L., and Belcher, S. E.: A case study of boundary layer ventilation by convection and coastal processes, J. Geophys. Res., 112, doi:10.1029/2006JD007984, 2007.

Davis, S. R., Talbot, R., and Mao, H.: Transport and outflow to the North Atlantic in the lower marine troposphere during ICARTT 2004, Atmos. Chem. Phys. Discuss., 12, 2395-2434, doi:10.5194/acpd-12-2395-2012, 2012.

Dickerson, R. R., Rhoads, K. P., Carsey, T. P., Oltmans, S. J., Burrows, J. P., and Crutzen, P. J.: Ozone in the remote marine boundary layer: A possible role for halogens, J. Geophys. Res., 104, 21385-21395, 1999.

Donnell, E. A., Fish, D. J., Dicks, E. M., and Thorpe, A. J.: Mechanisms for pollutant transport between the boundary layer and free troposphere, J. Geophys. Res., 106, doi:10.1029/2000JD900730, 2001

Fairall, C. W., Bariteau, L., Grachev, A. A., Hill, R. J., Wolfe, D. E., Brewer, W. A., Tucker, S. C., Hare, J. E., and Angevine, W. M.: Turbulent bulk transfer coefficients and ozone depletion velocity in the International Consortium for Atmospheric Research into Transport and Transformation, J. Geophys. Res., 111, doi:10.1029/2006JD007597, 2006.

Fang, Y., Fiore, A. M., Horowitz, L. W., Gnanadesikan, A., II, H. L., Hu, Y., and Russell, A. G.: Estimating the contribution of strong daily export events to total pollutant export from the United States in summer, J. Geophys. Res., 114, doi:10.1029/2008JD010946., 2009.

Fehsenfeld, F. C., Ancellet, G., Bates, T. S., Goldstein, A. H., Hardesty, R. M., Honrath, R., Law, K. S., Lewis, A. C., Leaitch, R.,
McKeen, S., Meagher, J., Parrish, D. D., Pszenny, A. A. P., Russel, P. B., Schlager, H., Seinfeld, J., Talbot, R., and Zbinden, R.: International Consortium for Atmospheric Research on Transport and Transformation (ICARTT): North America to Europe Overview of the 2004 summer field study, J. Geophys. Res., 111, doi:10.1029/2006JD007829, 2006.

Holzer, M. and Hall, T. M.: Low-level trans-Pacific transport, J. Geophys. Res., 112, doi:10.1029/2006JD007828, 2007.

Lee, S. H., Kim, S.-W., Trainer, M., Frost, G. J., McKeen, S. A., Cooper, O. R., Flocke, F., Holloway, J. S., Neuman, J. A., Ryerson, T., Senff, C. J., Swanson, A. L., and Thomson, A. M.: Modeling ozone plumes observed downwind of New York City over the North Atlantic Ocean during the ICARTT field campaign, Atmos. Chem. Phys., 11, 7375-7397, doi:10.5194/acp-11-73752011, 2011.

Lock, A. P., Brown, A. R., Bush, M. R., Martin, G. M., and Smith, R. N. B.: A New Boundary Layer Mixing Scheme. Part I: Scheme Description and Single-Column Model Tests, Mon. Wea. Rev., 128, 3187-3199, 2000.

Methven, J., Arnold, S. R., Stohl, A., Evans, M. J., Avery, M., Law, K., Lewis, A. C., Monks, P. S., Parrish, D. D., Reeves, C. E., Schlager, H., Atlas, E., Blake, D. R., Coe, H., Crosier, J., Flocke, F. M., Holloway, J. S., Hopkins, J. R., McQuaid, J., Purvis, R., Rappenglück, B., Singh, H. B., Watson, N. M., Whalley, L. K., and Williams, P. I.: Establishing Lagrangian connections between observations within air masses crossing the Atlantic during the International Consortium for Atmospheric Research on Transport and Transformation, J. Geophys. Res., 111, doi:10.1029/2006JD007540, 2006.

Müller, D., Franke, K., Wagner, F., Althausen, D., Ansmann, A., Heintzenberg, J., and Verver, G.: Vertical profiling of optical and physical particle properties over the tropical Indian Ocean with six-wavelength lidar 2. Case studies, J. Geophys. Res., 106, 28577-28595, 2001.

Owen, R. C., Cooper, O. R., Stohl, A., and Honrath, R. E.: An analysis of the mechanisms of North American pollutant transport to the central North Atlantic lower free troposphere, J. Geophys. Res., 111, doi:10.1029/2006JD007062, 2006.

Paluch, I. R., Lenschow, D. H., Hudson, J. G., and Peasron Jr., R.: Transport and Mixing Processes in the Lower Troposphere over the Ocean, J. Geophys. Res., 97, 7527-7541, 1992.

Real, E., Law, K. S., Schlager, H., Roiger, A., Huntrieser, H., Methven, J., Cain, M., Holloway, J., Neuman, J. A., Ryerson, T., Flocke, F., de Gouw, J., Atlas, E., Donnelly, S., and Parrish, D.: Lagrangian analysis of low altitude anthropogenic plume processing across the North Atlantic, Atmos. Chem. Phys., 8, 7737 7754, doi:10.5194/acp-8-7737-2008, 2008.

Skyllingstad, E. D., Samelson, R. M., Mahrt, L., and Barbour, P.: A Numerical Modeling Study of Warm Offshore Flow over Cool Water, Mon. Wea. Rev., 133, 3-361, 2005.

Sze, N. N.: Anthropogenic CO emissions: Implications for the atmospheric CO-OH-CH4 cycle, Science, 195, 673-675, 1977.

VanCuren, R. A., Cliff, S. S., Perry, K. D., and Jimenez-Cruz, M.: Asian continental aerosol persistence above the marine boundary layer over the eastern North Pacific: Continuous aerosol measurements from Intercontinental Transport and Chemical Transformation 2002 (ITCT 2K2), J. Geophys. Res., 110, doi:10.1029/2004JD004973, 2005. 
Verma, S., Boucher, O., Venkataraman, C., Reddy, M. S., Müller, D., Chazette, P., and Crouzille, B.: Aerosol lofting from sea breeze during the Indian Ocean Experiment, J. Geophys. Res., 111, doi:10.1029/2005JD005953, 2006.

Vickers, D., Mahrt, L., Sun, J., and Crawford, T.: Structure of Offshore Flow, Mon. Wea. Rev., 129, 1251-1258, 2001.
Wolfe, D. E., Brewer, W. A., Tucker, S. C., White, A. B., White, D. E., Welsh, D. C., Ruffieux, D., Fairall, C. W., Ratterree, M., Intrieri, J. M., McCarty, B. J., and Law, D. C.: Shipboard multisensor merged wind profiles from the New England Air Quality Study 2004, J. Geophys. Res., 112, doi:10.1029/2006JD007344, 2007. 